\title{
Traduir ciència
}

\author{
Joandomènec Ros \\ Catedràtic emèrit d'Ecologia \\ Universitat de Barcelona. Facultat de Biologia \\ 08028 Barcelona \\ jros@ub.edu
}

President de l'Institut d'Estudis Catalans

Institut d'Estudis Catalans

08001 Barcelona

jros@iec.cat

\section{Resum}

Traduir textos científics, siguin manuals universitaris, llibres o articles de divulgació científica o assaigs, obliga a una literalitat que quan es tracta de traduir ficció (i en especial poesia) no cal que sigui respectada. La fidelitat al text original, tal com el concebé l'autor, sempre necessària, és absoluta quan allò que es transmet és ciència. Tanmateix, en alguna ocasió aquesta fidelitat pot ser mal interpretada pel lector. Es presenten alguns casos, en especial un en el qual l'autor fou acusat de censurar el text original.

Paraules clau: traduir ciència; divulgació científica; modificació dels originals; censura; opinió dels lectors; Stephen J. Gould; Yuval N. Harari; Edward O. Wilson

\section{Abstract. Translating science}

Translating scientific texts, whether they are university textbooks, books or papers popularizing science or scientific essays, requires a literal meaning that when it comes to translating fiction (and especially poetry) it does not have to be respected. Fidelity to the original text, exactly as the author devised it, always necessary, is absolute when conveying science. However, sometimes the reader can misinterpret this fidelity. Some cases are presented, especially one in which the author was accused of censoring the original text.

Keywords: translating science; popularizing science; modifying originals; censorship; readers input; Stephen J. Gould; Yuval N. Harari; Edward O. Wilson

\section{Sumari}

Trair a qui es tradueix Les raons de la «traïció»

Traducció i censura Referències bibliogràfiques 
Un traductor diplomat, que diu que si tingués un cèntim per cada cop que ha obert un diccionari seria més ric que el rei del petroli, el rei del safrà, el rei de la seda i el virrei Amat.

Un traductor compulsivament infidel, a qui es perdonen les seves infidelitats escandaloses a causa d'una suposada influència que vindria de molt amunt...

(Albert Jané, Calidoscopi informal, p. 35 i 37)

Des de fa molts anys (gairebé cinc dècades) he fet de torsimany de diferents autors, sobretot de científics que escriuen manuals universitaris, que divulguen la ciència que conreen o que escriuen assaig sobre ciència, cultura o societat, però també de periodistes especialitzats en divulgació científica. La llengua de partida ha estat sobretot l'anglès (però també el francès, l'italià i el castellà) i la d'arribada majoritàriament el castellà, i en menor mesura el català (coses del mercat!). El resultat: gairebé dos centenars de llibres i tres-cents articles d'autors diversos, recercadors, universitaris i divulgadors que feien i fan quelcom més que escriure per les revistes especialitzades dels seus camps científics respectius o per als estudiants universitaris: ho fan per al gran públic, convençuts que cal que coneguin les beceroles de la ciència. És una convicció que comparteixo. Es tracta sobretot de biòlegs (genetistes, zoòlegs, antropòlegs, ecòlegs, naturalistes en definitiva), però també metges, físics, geòlegs, astrònoms i historiadors.

Molts d'aquests autors van molt més enllà de la divulgació o la docència: aboquen en els seus llibres assaigs sobre ciència, i ho fan no només a partir dels seus coneixements sectorials concrets, sinó pouant gairebé en tots els àmbits de les ciències, les humanitats i la cultura. Alguns han obtingut els premis més valorats dels seus àmbits, inclosos els Nobel; tots escriuen molt bé (han guanyat també premis a l'excel-lència literària, com el Pulitzer, l'Aventis, el Lewis Thomas o el Michael Faraday), i eren o són personalitats respectades en els seus cercles acadèmics; els seus llibres són èxits de vendes a tot el món. He gaudit traduint-los, pel que explicaven i per com ho feien, però també molts m'han fet patir, precisament pel seu domini de la llengua i de la cultura universal.

Entre aquests autors n'hi ha de clàssics, com Charles Darwin, Rachel Carson i G. Evelyn Hutchinson, i de contemporanis, com Hugh Aldersey-Williams, Walter Alvarez, Francisco J. Ayala, Michael Brooks, Antonio R. Damasio, Richard Dawkins, Christian de Duve, Freeman Dyson, Clive Finlayson, Richard Fortey, Adam Frank, Yuval N. Harari, Richard C. Lewontin, Ramon Margalef, J. Maynard Smith, Howard T. Odum, John Postgate, Martin Rees, James D. Watson, David Wootton. I, sobretot, Stephen J. Gould i Edward O. Wilson. Precisament, s'ha dit de mi que soc el «traductor oficial» de Stephen J. Gould (deu llibres traduïts, i uns altres tants de revisats o compilats), però es podria dir el mateix d'Edward O. Wilson (set llibres), Charles Darwin, Antonio R. Damasio, Michael Brooks i Yuval N. Harari (tres de cadascu), etc. (Ros 2003, 2006, 2016, en premsa). 


\section{Trair a qui es tradueix}

Són nombrosos els exemples de tot tipus que avalen la dita segons la qual Traduttore, traditore: el traductor traeix l'autor original i li fa dir coses que realment no digué (o no escrigué). Això pot deure's a alguna de les raons següents: $i$ ) per tal de cercar una millor adequació a l'entorn social i cultural del lector; ii) per conservar la rima (en el cas de la poesia); iii) per modificar conscientment (i, per tant, estrafer o censurar) el text original: alguns traductors se senten sovint autors complementaris dels autors reals que tradueixen, i s'hi creuen autoritzats. Sense descartar, és clar: $i v$ ) les limitacions pròpies del traductor en la llengua de partida o en la d'arribada: d'on no n'hi ha, no en pot rajar, diu el refrany.

No he traduït mai poesia, de manera que no he tingut ocasió d'estrafer obra poètica original (opció $i i$ ). Pel que fa a l'opció $i v$, algun cop he rebut, directament o a través de l'editorial corresponent, missatges de lectors a qui no ha agradat la meva traducció, en general o per algun aspecte concret. Solen ser observacions adients, de les que n'he tret ensenyaments útils (més que de les persones que m'han elogiat aquesta o aquella traducció... que també n'hi ha, entre ells els mateixos autors!). Aquests lectors disconformes es queixen sovint d'algun fals amic que inadvertidament s'ha introduït en el text, o de construccions lèxiques que revelen que la meva llengua materna és la catalana. Com que jo mateix no m'he estat de criticar, públicament, traduccions equivocades (Ros 1999), accepto els meus errors, quan hi són.

I, també sovint, hi ha lectors que es queixen sense motius, per exemple perquè el traductor (i l'editorial) han fet cas de les darreres modificacions ortogràfiques de la Real Academia Española o de l'Institut d'Estudis Catalans, tant pel que fa als accents que es perden com per la transliteració d'alguns termes forans. $\mathrm{O}$ bé perquè els coneixements del lector són limitats: recordo un cas concret en què qui es queixava ho feia, entre altres coses, perquè, a parer seu, el cognom del filòsof Baruch Spinoza (Damasio 2005) havia de ser Espinosa (!). Un altre lector es queixava perquè jo havia traduït massa literalment unes frases de l'autor (Wilson 2018), i no s'entenien: calia que jo hagués estat més «creatiu» (ergo, que estrafés l'original) en benefici dels lectors. Les frases concretes eren aquestes (les acompanyo de la meva versió, que l'editorial va respectar, i d'altres opcions possibles):

Original: And as the moon rose higher the inessential house began to melt away until gradually...

La meva traducció: Y mientras la luna se elevaba cada vez más, la casa innecesaria empezó a difuminarse hasta que gradualmente...

Dels diccionaris: inessential: superflua, innecesaria

Original: In yet another medium, photography, Rachel Sussman's collection The Oldest Things in the World presents candidate trees and other plants thousands of years in age. 
La meva traducció: Todavía en otro medio, la fotografía, la colección The Oldest Things in the World, de Rachel Sussman, presenta árboles y otras plantas candidatas de miles de años de edad.

Dels diccionaris: candidate: candidato, postulante, aspirante

Original: Some of the best signatures within the creative arts do not just surprise the aesthetic sense, they astonish it.

La meva traducció: Algunas de las mejores rúbricas en el seno de las artes creativas no solo sorprenden el sentido estético, lo asombran.

Amb alguns dels autors que he traduit — pocs - hi he mantingut contactes, epistolars o directes quan hem coincidit personalment, per aclarir algun dubte dels seus llibres o articles; altres autors, o els editors, han demanat expressament que un manual universitari o una guia de camp s'adaptessin a la realitat espanyola, mediterrània o europea, segons els casos, la qual cosa vol dir que, a més de traductor, he fet d'adaptador o de coautor (per exemple, Campbell 1977; Cognetti et al. 2001; Primack i Ros 2002).

De vegades són els mateixos autors de les obres originals els qui suggereixen als traductors, de manera genèrica, les adaptacions que poden fer (la qual cosa correspon al primer dels casos citats més amunt: $i$ ). Això és el que sol fer Yuval Noah Harari, en cadascun dels tres llibres d'aquest autor israelià que he traduït a l'espanyol: Sapiens. De animales a dioses (Harari 2014a), Homo Deus (2016) i 21 lecciones para el siglo XXI (2018). Per exemple, en una «Nota per als traductors» d'aquest últim llibre, Harari suggereix:

Si vostès troben [en els originals de l'autor] alguns exemples amb els quals el públic local podria estar poc familiaritzat, sentin-se lliures de suggerir en el seu lloc algun exemple local similar, però, si us plau, acordin aquest canvi amb mi.

No obstant això, mai he fet cas de tals suggeriments, ni d'Harari ni dels altres autors que he traduiit (excepte els casos concrets, suggerits pels autors o els editors, esmentats més amunt), ni m'he pres tals llibertats pel meu compte. Traduir ciència (encara que sigui per divulgar-la, és a dir, escrita en un llenguatge no tan envitricollat com els textos tècnics de les ciències, especialment de les dites «dures») obliga a ser molt respectuós amb l'original, molt més que quan es tradueix ficció i, no diguem, poesia. En qualsevol cas, sempre queda el recurs d'afegir una nota del traductor explicativa, encara que sense abusar d'aquesta possibilitat per no entorpir-ne la lectura.

\section{Traducció i censura}

Però anem a l'opció iii que jo distingia més amunt: la modificació a consciència d'un text per raons espúries. Vet aquí que en un article de Manuel Peña Díaz, «Traducción y censura» (2018), els exemples històrics que aquest autor propor- 
ciona de la censura en diferents traduccions literàries culminen amb una referència gens agradosa a una de les meves traduccions d'Harari, en concret de Sapiens. El Sr. Peña es fa ressò d'un article previ (Anònim, 2018) que jo no vaig conèixer fins que vaig llegir el del Sr. Peña. Segons aquest darrer, he exercit una suposada «censura» en haver substituït presumptament les ciutats angleses d'Oxford i Cambridge per Madrid i Barcelona en un context de cultures contraposades. Tant el Sr. Peña com l'anònim autor de Dolça Catalunya s'equivoquen de mig a mig.

El fragment de l'original anglès que jo vaig traduir, a partir del pdf que l'editorial israeliana va facilitar a l'editorial espanyola (Harari, 2012), diu textualment:

For example, there's every reason to believe that a forager band that lived 30,000 years ago on the spot where Madrid now stands would have spoken a different language from one living where Barcelona is now situated. One band might have been belligerent and the other peaceful. Perhaps the Castilian band was communal while the Catalan one was based on nuclear families. The ancient Castilians might have spent long hours carving wooden statues of their guardian spirits, whereas their Catalan contemporaries may have worshiped through dance. The former perhaps believed in reincarnation, while the latter thought this was nonsense. In one society, same-sex sexual relationships might have been accepted, while in the other they were taboo. (Harari 2012: 57)

La meva versió fou aquesta:

Por ejemplo, existen razones para creer que una banda de cazadores-recolectores que viviera hace 30.000 años en el lugar en el que ahora se encuentra Madrid habría hablado un lenguaje diferente de una cuadrilla que viviera donde ahora está situada Barcelona. Una banda pudo haber sido belicosa y la otra pacífica. Quizá la banda castellana era comunal, mientras que la catalana se basaba en familias nucleares. Los antiguos castellanos pudieron haber pasado muchas horas esculpiendo estatuas de madera de sus espíritus guardianes, mientras que sus contemporáneos catalanes quizá adoraran mediante la danza. Quizá los primeros creyeran en la reencarnación, mientras que los otros creyeran que esto eran tonterías. En una sociedad, podrían haberse aceptado las relaciones sexuales entre personas del mismo sexo, mientras que en la otra podrían haber sido tabú. (Harari 2014a: 60-61)

En aquest $\mathrm{i}$ en altres passatges de les obres d'Harari és palès l'ampli coneixement d'aquest autor d'èxit, no solament de la història universal, sinó de molts aspectes culturals, socials, etc., de països diversos, com Espanya, la qual cosa fa tan interessants les seves anàlisis del passat $i$ del present $i$ les seves prospectives del futur (i explica les nombroses edicions dels seus llibres). El text anterior és, ho diu l'autor, un exemple que vol explicar l'aïllament cultural en les comunitats humanes del passat, i va triar aquestes dues ciutats com podia haver triat Milà i Roma, París i Lió, Bagdad i Damasc o, efectivament, Oxford i Cambridge. Però va triar Madrid i Barcelona, i així ho vaig deixar en la meva traducció.

Però anem al penjament que el Sr. Peña i l'anònim autor previ em dediquen injustament. 
Suposo que en l'edició anglesa del Regne Unit (Harari 2014b) l'adaptador (o editor, ja que no traductor: l'original era en llengua anglesa) va canviar les ciutats originals de Madrid i Barcelona d'Harari per Oxford i Cambridge (p. 45; de fet, s'hi esmenta «la Universitat d'Oxford» $\mathrm{i}$ «la ciutat de Cambridge»), perquè potser va pensar que «el públic local podria estar poc familiaritzat» (tal com deia Harari en la seva «Nota per als traductors») amb les dues ciutats espanyoles i amb la seva pugna cultural (com la que existeix des d'antic entre les dues ciutats universitàries angleses).

Alguna cosa semblant va fer el traductor de la versió catalana (Harari 2014c: 74) en substituir Madrid per Lleida, tot deixant la Barcelona de l'original, amb la qual cosa feia més local (i menys sagnant) la comparació original. He comentat irònicament aquest últim cas en la meva presentació de dos volums sobre la identitat catalana coordinats per Flocel Sabaté (2015a, b).

És lamentable, d'altra banda, que, consultada per l'autor anònim de Dolça Catalunya l'editorial responsable de les publicacions d'Harari en espanyol sobre aquesta suposada tergiversació del text original, la resposta d'aquesta (que es va fer sense consultar-me) donava per descomptat que, efectivament, jo havia alterat la traducció: «...l'autor va demanar que s'adaptessin els exemples en les traduccions...», «...utilitzem Madrid i Barcelona per ser dues de les ciutats de parla hispana més conegudes del món». Ja he explicat què deia, l'original de Sapiens.

\section{Les raons de la «traïció»}

Què podria haver-me impel-lit a efectuar aquest suposat canvi de ciutats en l'exemple d'Harari? L'autor anònim de Dolça Catalunya, i després el Sr. Peña, creuen saber-ho: resulta que sóc el president de l'Institut d'Estudis Catalans, que he fet declaracions a ràdio i televisió sobre quin hauria de ser l'idioma preferent (el català, és clar) en una futura Catalunya independent, i que vaig «promoure» (acollir a la seu de l'IEC, realment) el simposi «Espanya contra Catalunya» (Sobrequés 2015). Tot això, segons ells, explica la meva malèvola (i censurada) traducció. En resum: segons aquests dos sagaços escriptors en mitjans de la premsa digital groga, he volgut afegir més llenya al foc a la manca d'acord entre Catalunya i Espanya.

Potser no cal dir que, quan vaig exercir el meu dret de rèplica i vaig enviar al mitjà en què havia sortit l'article del Sr. Peña una nota demanant que rectifiquessin el text o que em publiquessin la nota aclaridora dels fets (molt més curta que aquest escrit), no vaig tenir cap resposta.

En resum, de censura en la meva traducció, cap; simplement, fidelitat total a l'original. Aquest ha estat el meu lema al llarg del gairebé mig segle d'exercici de torsimany. Si el Sr. Peña i/o l'autor anònim de Dolça Catalunya volien estar informats de la meva manera de traduir podrien haver compulsat amb els originals respectius qualsevol dels llibres o articles de divulgació científica o assaig que he traduït al llarg de la meva vida activa. $\mathrm{O}$, encara millor: per saber-ho de primera mà m'ho podien haver preguntat directament a mi; o, encara, podien haver consultat les meves reflexions d'un traductor científic sobre la grandesa i la servitud de l'ofici, publicades en dos articles (Ros 2004, 2005) i reproduïdes en un dels meus llibres (Ros 2006). 


\section{Referències bibliogràfiques}

(2018). «Un nacionalista falsea una traducción para decir que hace 30.000 años en 'Madrid' eran 'belicosos', pero en Barcelona 'pacíficos'». (6 març). <https://www. dolcacatalunya.com/2018/03/nacionalista-falsea-una-traduccion-decir-30-000-anosmadrid-belicosos-barcelona-pacificos $>$.

Campbell, A. C. (1977). Guía de campo de la flora y fauna de las costas de España y de Europa. Barcelona: Omega.

Cognetti, G.; SarÀ, M.; Magazzù, G. (2001). Biología marina. Barcelona: Ariel.

Damasio, A. (2005). En busca de Spinoza. Neurobiología de la emoción y los sentimientos. Barcelona: Crítica.

Harari, Y. N. (2012). Sapiens. From Animals into Gods. A Brief History of Humanity. Jerusalem [sense menció d'editorial]. Barcelona: Crítica.

- (2014a). Sapiens. De animales a dioses. Breve historia de la humanidad. Barcelona: Debate, Penguin Random House.

- (2014b). Sapiens. A Brief History of Humankind. Londres: Harvill Secker.

- (2014c). Sàpiens. Una breu història de la humanitat. Barcelona: Edicions 62.

- (2016). Homo Deus. Breve historia del mañana. Barcelona: Debate, Penguin Random House.

- (2018). 21 lecciones para el siglo XXI. Barcelona: Debate, Penguin Random House.

Jané, A. (2017). Calidoscopi informal. Girona: Edicions de la Ela Geminada.

PeÑa Díaz, M. (2018). «Traducción y censura». A: Letra global (31 maig). <https://cronicaglobal.elespanol.com/letra-global/el-dossier/traduccion-censura_144221_102.html>

Primarck, R. B.; Ros, J. D. (2002). Introducción a la biología de la conservación. Barcelona: Ariel.

Ros, J. D. (1999). Proposicions il-luminadores i insensates. Reflexions sobre ciència. Barcelona: Empúries.

- (2003). «El evolucionista laureado de América». A: Ros, J. D. (ed.). Stephen Jay Gould. Obra esencial. Barcelona: Crítica.

- (2004). «Reflexons de um tradutor científico sobre a grandeza e a servidom do oficio». A: Garrido, C. (ed.). Ferramentas para a traduçom, p. 11-26. Ourense: Associaçom Galega da Língua.

- (2005). «Reflexiones de un traductor científico sobre la grandeza y la servidumbre del oficio».Panace@, 6 (19),p.4-10.

- (2006). Exploració, joc i reflexió. Assaigs sobre ciència. Lleida: Pagès.

— (2015a). «Presentació». A: Anàlisi històrica de la identitat catalana (F. Sabaté, ed.) :7-8. Barcelona: Institut d'Estudis Catalans.

- (2015b). «Preface». A: Historical Analysis of the Catalan identity (F. Sabaté, ed.) :7-11. Berna, etc.: Peter Lang.

- (2016). La saviesa combinada. Reflexions sobre ecologia i altres ciències. Barcelona: Publicacions de la Universitat de Barcelona.

- (en premsa). «L'assaig científic vist per l'autor i pel traductor».

Sobrequés, J. (ed.). (2015). Vàrem mirar ben al lluny del desert. Actes del simposi «Espanya contra Catalunya: una mirada històrica (1714-2014)». Barcelona: Departament de la Presidència, Generalitat de Catalunya. Centre d'Història Contemporània de Catalunya.

Wilson, E. O. (2018). Los orígenes de la creatividad humana. Barcelona: Crítica. 
